\title{
Comparison of the cloud top heights retrieved from MODIS and AHI satellite data with ground-based Ka-band radar
}

\author{
Juan Huo, Daren Lu, Shu Duan, Yongheng Bi, and Bo Liu \\ Correspondence: Juan Huo (huojuan@mail.iap.ac.cn) \\ Received: 15 July 2019 - Discussion started: 28 August 2019 \\ Revised: 7 November 2019 - Accepted: 21 November 2019 - Published: 2 January 2020
}

Key Laboratory for Atmosphere and Global Environment Observation, Chinese Academy of Sciences, Bejing, 100029, China

\begin{abstract}
To better understand the accuracy of cloud top heights (CTHs) derived from passive satellite data, groundbased Ka-band radar measurements from 2016 and 2017 in Beijing are compared with CTH data inferred from the Moderate Resolution Imaging Spectroradiometer (MODIS) and the Advanced Himawari Imager (AHI). Relative to the radar CTHs, the MODIS CTHs are found to be underestimated by $-1.10 \pm 2.53 \mathrm{~km}$ on average and $49 \%$ of $\mathrm{CTH}$ differences are within $1.0 \mathrm{~km}$. The AHI CTHs are underestimated by $-1.10 \pm 2.27 \mathrm{~km}$ and $42 \%$ are within $1.0 \mathrm{~km}$. Both the MODIS and AHI CTH retrieval accuracy depends strongly on the cloud depth (CD). Large differences are mainly due to the retrieval of thin clouds of $C D<1 \mathrm{~km}$, especially when the cloud base height is higher than $4 \mathrm{~km}$. For clouds with $\mathrm{CD}>1 \mathrm{~km}$, the mean CTH difference decreases to $-0.48 \pm 1.70 \mathrm{~km}$ for MODIS and to $-0.76 \pm 1.63 \mathrm{~km}$ for AHI. It is found that MODIS CTHs with higher values (i.e. $>6 \mathrm{~km}$ ) show smaller discrepancy with radar $\mathrm{CTH}$ than those MODIS CTHs with lower values (i.e. $<4 \mathrm{~km}$ ). Statistical analysis illustrate that the CTH difference between the two satellite instruments is lower than the difference between the satellite instrument and the ground-based Ka-band radar. The monthly accuracy of both CTH retrieval algorithms is investigated and it is found that summer has the smallest retrieval difference.
\end{abstract}

\section{Introduction}

Clouds play important role in the water and energy budgets in the Earth-atmosphere system (Ramanathan et al., 1989; Liou, 1992; Cess et al., 1996; Boucher et al., 2013). They are one of the least understood components, and also one of the largest uncertainty sources, in general circulation model (GCM) simulations (Wetherald and Manabe, 1988; Arakawa, 2004). Cloud top height (CTH) is one of the important cloud parameters that provide information about the vertical structure of cloud water content (Stubenrauch et al., 1997; Marchand et al., 2010). Cloud vertical distributions determine diabatic heating profiles. Comparisons of stratocumulus CTHs simulated from GCMs with those retrieved from satellites suggested that either satellite retrievals placed stratocumulus clouds too high in the atmosphere or GCM cloud tops were biased too low (Rossow and Schiffer, 1999). Knowledge of $\mathrm{CTH}$ is crucial to understanding the Earth's radiation budget and global climate change.

Active and passive instruments have long been used for monitoring CTHs (Atlas, 1954; Schiffer and Rossow, 1983; Pavolonis and Heidinger, 2004; Stephens and Kummerow 2007; Huo and Lu 2009; Görsdorf et al., 2015). Active instruments, i.e. cloud radars and lidars, detect CTH directly through reflectivity from cloud top particles. Passive infrared (IR) instruments measure the IR brightness temperature of the cloud to derive CTH based on assumptions, for instance, that an opaque cloud could be regarded as a black body. Surface measurements and satellite measurements have individual strengths and weaknesses. Some active instruments, i.e. radar, are ideal sensors for accurately detecting the CTH. Yet, surface instruments are limited in spatial scale. Satellites measure large-scale cloud systems, but the CTHs retrieved from passive IR instruments are still subject to large uncertainties. This study assesses the accuracy of the CTHs derived from passive satellites through comparison with surface active radar data. 
The Moderate Resolution Imaging Spectroradiometer (MODIS) on board the Aqua and Terra satellites has been in service since 2000 and its cloud products are being widely used by the meteorological community (King et al., 1998; Ackerman, 1998; Rodell and Houser, 2004; Roskovensky and Liou, 2006; Remer et al., 2008; Pincus et al., 2012). Uncertainties in the MODIS CTH products have been assessed using many measurements, i.e. from the ground, aircraft and satellites (Naud et al., 2002; Weisz et al., 2007; Ham et al., 2009; Chang et al., 2010; Marchand et al., 2010; Baum et al., 2012; Marchand, 2013; Xi et al., 2014; Håkansson et al., 2018; Wang et al., 2019). Naud et al. (2002) showed that the two sets of averaged CTHs from the Multi-Angle Imaging Spectroradiometer (MISR) and MODIS were generally within $2 \mathrm{~km}$ of each other over the British Isles. Holz et al. (2008) found that MODIS underestimated the CTH relative to the Cloud-Aerosol Lidar with Orthogonal Polarization (CALIOP) by $1.4 \pm 2.9 \mathrm{~km}$ globally over a 2 month period. $\mathrm{Xi}$ et al. (2014) found that daytime CTH of marine boundary layer cloud retrieved from MODIS was $0.063 \mathrm{~km}$ higher on average than what surface lidar and radar had measured. Håkansson et al. (2018) used global collection 6 MODIS cloud top products to compare with CloudSat cloud profiling radar data and reported that the mean difference was $-0.61 \pm 2.53 \mathrm{~km}$. Previous global evaluation results might be different to the specific regions. This study compares the retrieved MODIS CTHs with radar measurements in Beijing over a long period and provides further knowledge about the uncertainty of MODIS CTH products.

The Advanced Himawari Imager (AHI) on board the Himawari-8 (HW8) satellite, a geostationary meteorological satellite, has provided CTHs since July 2015 (Bessho et al., 2016). Zhou et al. (2019) reported that the CTHs derived from surface Ka-band radar from December 2016 to November 2017 were $0.82 \mathrm{~km}$ higher than the retrieved CTH from the AHI radiance data using a Fengyun Geostationary Algorithm Testbed-Imager (FYGAT-I) science product algorithm. Mouri et al. (2016) reported that the mean AHI CTH was lower than the MODIS and CALIOP CTH over 2 weeks of measurements. The AHI CTH retrievals are relatively new to the meteorological community and require further evaluation before application in meteorological studies.

MODIS and AHI share some common principles and technologies used for the CTH retrieval. However, the specific retrieval algorithms are different in terms of the radiative transfer model, atmospheric profiles, source measurements and cloud types. A Ka-band $(35.075 \mathrm{GHz})$ radar at the Institute of Atmospheric Physics in Beijing, China $\left(39.96^{\circ} \mathrm{N}\right.$, $\left.116.37^{\circ} \mathrm{E}\right)$, has been used for cloud measurements since 2012 (Huo et al., 2019). In this study, we compare and evaluate the CTHs retrieved from the passive satellite instruments on board a polar-orbiting satellite and a geostationary satellite with those measured by a surface active radar in Beijing over a long period. To our knowledge, this study presents the first comparison and evaluation of the $\mathrm{CTH}$ datasets for Bei- jing from MODIS and AHI. This work quantifies the satellite CTH retrieval accuracy and provides a reference and usage guidance for the application of the CTH datasets in meteorological research, such as climate model simulations for Beijing and northern China.

\section{Description of the MODIS, AHI and Ka-band radar CTH retrievals}

\subsection{MODIS CTH retrieval}

MODIS measures radiance in 36 spectral bands from 0.42 to $14.24 \mu \mathrm{m}$ at three spatial resolutions: 250,500 and $1000 \mathrm{~m}$. The swath dimensions are $2330 \mathrm{~km}$ (cross-track) by $10 \mathrm{~km}$ (along-track at nadir). MODIS cloud top pressure (height) is determined by a combination algorithm of $\mathrm{CO}_{2}$-slicing technology (also known as the radiance ratioing technology) and infrared window technology (IRW, using the $11 \mu \mathrm{m}$ brightness temperature, Smith and Platt, 1978; Nieman et al., 1993) in conjunction with the National Center for Environmental Prediction Global Data Assimilation System temperature profiles (Menzel et al., 2008; Baum et al., 2012). Equations (1)-(3) below present the basic theory of the $\mathrm{CO}_{2}$ slicing technology for which Menzel et al. (2008) presented thorough descriptions.

$$
\begin{aligned}
& R(v)=(1-\mathrm{NE}) R_{\mathrm{clr}}(v)+\mathrm{NE}\left[R_{\mathrm{bcd}}\left(v, P_{\mathrm{c}}\right)\right] \\
& R_{\mathrm{bcd}}\left(v, P_{\mathrm{c}}\right)=R_{\mathrm{clr}}(v) \int_{P_{\mathrm{c}}}^{P_{\mathrm{s}}} \tau(v, p) \frac{\mathrm{d} B[v, T(p)]}{\mathrm{d} p} \mathrm{~d} p \\
& \frac{R(v 1)-R_{\mathrm{clr}}(v 1)}{R(v 2)-R_{\mathrm{clr}}(v 2)}=\frac{\mathrm{NE} 1 \int_{P_{\mathrm{s}}}^{P_{\mathrm{c}}} \tau(v 1, p) \frac{\mathrm{d} B[v 1, T(p)]}{\mathrm{d} p} \mathrm{~d} p}{\mathrm{NE} 2 \int_{P_{\mathrm{s}}}^{P_{\mathrm{c}}} \tau(v 2, p) \frac{\mathrm{d} B[v 2, T(p)]}{\mathrm{d} p} \mathrm{~d} p}
\end{aligned}
$$

Here $v$ is the frequency, $E$ is the emissivity of cloud, $R(v)$ is the measured radiance, $R_{\mathrm{clr}}$ is the radiance of clear sky and $R_{\text {bcd }}$ is the radiance of black body. $N$ is the cloud coverage of the field of view in the range of $0 \sim 1, \tau(v, p)$ is the fractional transmittance of radiation at the wavelength $v$ from the atmospheric pressure level $(p)$ arriving at the top of the atmosphere $(p=0), P_{\mathrm{c}}$ is the cloud top pressure, $B[v, T(p)]$ is the Planck radiance at the wavelength $v$ at the temperature $T(p)$ and $P_{\mathrm{S}}$ is the surface pressure. The $\mathrm{CO}_{2}$-slicing technology assumes the emissivity of the cloud to be the same at two close wavelengths, which is nearly correct for ice clouds but less so for water clouds.

For the $\mathrm{CO}_{2}$-slicing technology, Terra-MODIS CTHs are retrieved based on the channels $36 / 35$ and 35/33 (corresponding to $14.2 / 13.94$ and $13.94 / 13.34 \mu \mathrm{m}$ ) ratio pairs due to noise problems at band 34. Aqua-MODIS CTHs are retrieved by the following three ratio pairs: channels $36 / 35$, channels 35/34, channels 34/33 (14.2/13.94, 13.94/13.64, $13.64 / 13.34 \mu \mathrm{m})$. In the collection 5 version algorithm, when the radiance difference between cloud and clear sky is so 


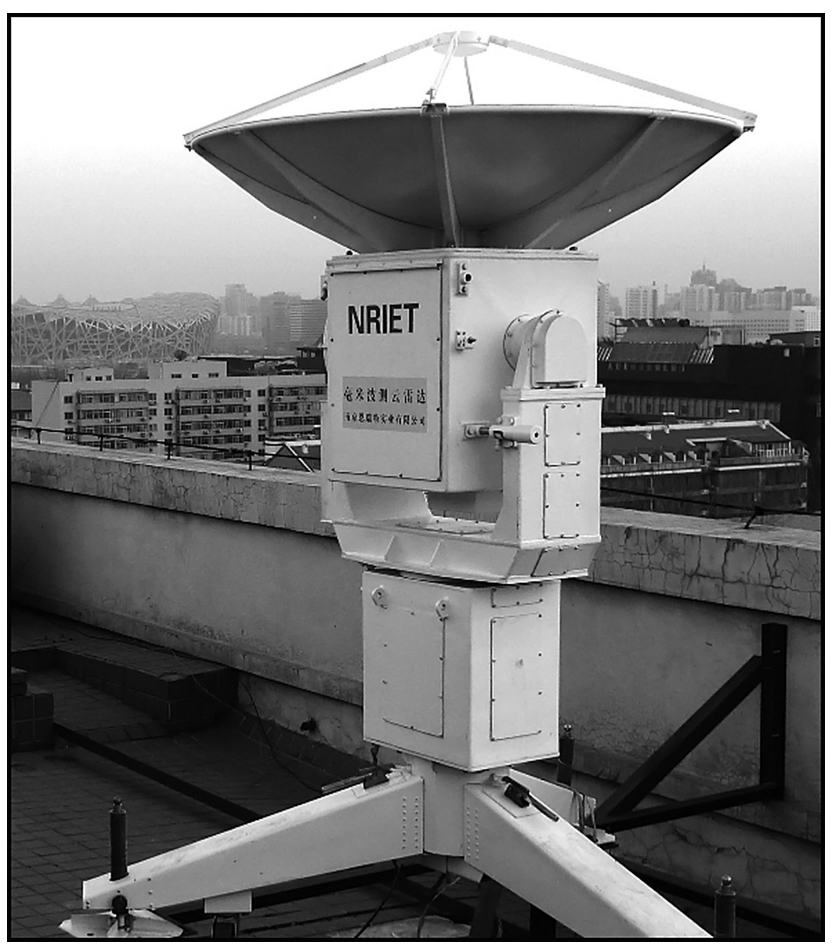

Figure 1. The Ka-band polarization Doppler radar at the Institute of Atmospheric Physics, Chinese Academy of Sciences, Beijing, China $\left(39.967^{\circ} \mathrm{N}, 116.367^{\circ} \mathrm{E}\right)$.

small that $\mathrm{CO}_{2}$-slicing technology is unsuitable for $\mathrm{CTH}$ retrieval, the IRW is applied. Compared with the collection 5 version algorithm, collection 6 differs in terms of the spatial resolution and the radiative transfer model calculation, for example, using ozone profiles provided in the meteorological products rather than from climatological values. Furthermore, application of the $\mathrm{CO}_{2}$-slicing method is limited to only ice cloud in collection 6 (Baum et al., 2012). The MODIS cloud products used in this study are the collection 6 version cloud datasets (MYD06/MOD06) from both Aqua and Terra at $1 \mathrm{~km}$ spatial resolution.

\subsection{AHI CTH retrieval}

The HW8 satellite, equipped with the AHI, was launched on 7 October 2014 at the location of $140.7^{\circ} \mathrm{E}$ and its operation by the Japanese Meteorological Agency commenced on 7 July 2015 (Bessho et al., 2016). The AHI is a visible infrared radiometer that has 16 observation bands, ranging from 0.47 to $13.3 \mu \mathrm{m}$ ( 3 for visible, 3 for near-infrared and 10 for infrared). The AHI observes the Japanese area and some other target or landmark areas every $2.5 \mathrm{~min}$ and the entire full disk every $10 \mathrm{~min}$ with a spatial resolution of $0.5-$ $2.0 \mathrm{~km}$. The scan ranges for full disk and the Japanese area are preliminarily fixed, while those for the target and landmark areas are flexible regarding meteorological conditions. Relative to the imagers on board previous Japanese geosta-
Table 1. Main technical specifications of the Ka radar at the IAP.

\begin{tabular}{lll}
\hline & Parameters & $\begin{array}{l}\text { Technical } \\
\text { specification }\end{array}$ \\
\hline \multirow{2}{*}{ Transmitter } & Frequency & $35.075 \mathrm{GHz}$ \\
& Peak power & $29 \mathrm{~kW}$ \\
& Pulse width & $0.2 \mu \mathrm{s}$ \\
& Type & Magnetron \\
& Pulse repetition frequency & $3.5 \mathrm{kHz}$ \\
\hline \multirow{2}{*}{ Antenna } & Diameter & $1.5 \mathrm{~m}$ \\
& Gain & $54 \mathrm{~dB}$ \\
& Scanning mode & Vertically pointing \\
& Beam width & $0.4^{\circ}$ \\
\hline \multirow{2}{*}{ Receiver } & Noise & $5.8 \mathrm{~dB}$ \\
& Noise power & $-103 \mathrm{dBm}$ \\
& Vertical resolution & $30 \mathrm{~m}$ \\
\hline
\end{tabular}

tionary satellites, the AHI is improved in terms of its number of bands, spatial resolution, temporal frequency and radiometric calibration.

The AHI CTH retrieval algorithm uses radiative transfer codes (Eyre, 1991) developed by EUMETSAT and numerical weather prediction temperature and humidity profile data to calculate the radiance of four infrared bands (wavelengths 6.2, 7.3, 11.2 and $13.3 \mu \mathrm{m}$ ). It involves the interpolation method, the $\mathrm{CO}_{2}$-slicing method and the intercept method. The selection of method depends on the cloud type from AHI cloud type product (Neiman et al., 1993; Schmetz et al., 1993; Mouri et al., 2016). The interpolation method is similar to the IRW. The vertical profile of radiance at $11.2 \mu \mathrm{m}$ is calculated using radiative transfer codes and compared with the radiance observed by AHI. Cloud top height is then determined from the interpolation ratio of radiance between two levels sandwiching the observed radiance. The interpolation method is adopted for opaque and fractional cloud. The intercept method uses three scatter plots of observed radiances (containing $33 \times 33$ pixels around the target pixel) at two band pairs $(11.2 / 6.2,11.2 / 7.3$ and $11.2 / 13.3 \mu \mathrm{m})$ and the calculated black body radiance curve to determine cloud top height (which has the minimum pressure) from the intersection. The intercept method is used for semi-transparent cloud. In the retrieval process for optically thin (or semi-transparent) clouds, if the intercept method does not produce suitable results, the $\mathrm{CO}_{2}$-slicing method is applied. If this also fails to produce suitable results, the interpolation method is utilized. The AHI cloud products used in this study are the Himawari-8 Cloud Property data released through the JAXA's P-Tree System (https: //www.eorc.jaxa.jp/ptree/index.html, last access: 16 September 2019). 


\subsection{Ka-band radar}

The Ka-band polarization Doppler radar using a wavelength of $8.55 \mathrm{~mm}$ (Ka radar), situated at the Institute of Atmospheric Physics (IAP, 39.967 $\mathrm{N}, 116.367^{\circ} \mathrm{E}$ ), Beijing, China, was set up in 2010 (Fig. 1). The technical specifications of the Ka-band radar are given in Table 1. The Ka radar works $24 \mathrm{hd}^{-1}$ in a vertically pointing mode, except during special events, such as heavy rain or short-term collaborative observations with other instruments, when the mode is changed.

A data quality control approach using a combination of the threshold and median filter methods has been implemented to reduce the effects of clutter and noise on the radar reflectivity (Xiao et al., 2018). It is considered to be cloudy if the reflectivity profile contains more than three bins of radar reflectivity data higher than $-45 \mathrm{dBZ}$. Zhou et al. (2019) used a threshold of $-40 \mathrm{dBZ}$ for cloud determination because their Ka radar was equipped with an all-solid transmitter that was different to our Ka radar. A higher threshold might miss some clouds with weak returns.

For a cloudy profile, the CTH is determined as the height of the cloudy bin at the highest level. In order to compare with passive satellite data, for clouds detected in a period (i.e. within $10 \mathrm{~min}$ ), the radar $\mathrm{CTH}$ is calculated as the mean CTH of all cloudy profiles but not upper-level cloud if there are multilayer clouds. Note that the radar CTH differs when the upper-level cloud partially but not completely covers lowlevel cloud (see Fig. 2). For a cloudy profile, the cloud base height $(\mathrm{CBH})$ is determined by the lowest cloudy radar bin. The cloud depth (CD) is equal to the $\mathrm{CTH}$ minus the $\mathrm{CBH}$. The final $\mathrm{CBH}$ (or $\mathrm{CD}$ ) is the average value of all $\mathrm{CBHs}$ (or CDs).

\section{Comparison scheme}

A MODIS or AHI CTH pixel covers a larger area than a single profile of radar. The data repetition frequency also differs. Temporal and spatial collocation of the radar, MODIS and AHI data is critical to facilitate effective comparison and evaluation.

\subsection{Collocation of the MODIS and Ka radar}

A MODIS CTH pixel at sub-satellite point covers an area of about $1 \mathrm{~km}^{2}$; vertically pointed radar takes about $1.7 \mathrm{~min}$ to scan a $1 \mathrm{~km}$ path and about $8 \min$ for a $5 \mathrm{~km}$ path if the moving speed of cloud is $10 \mathrm{~m} \times \mathrm{s}^{-1}$. If the moving speed becomes higher (or lower), the required time scanning the same path will decrease (or increase). To compensate for the temporal and spatial differences in satellite data and groundbased data, Naud and Muller (2002) used MODIS CTH data averaged over a \pm 0.1 latitude-longitude box for comparison with surface radar data. Dong et al. (2008) used the surface data (on the southern Great Plains, SGP, USA, atmospheric
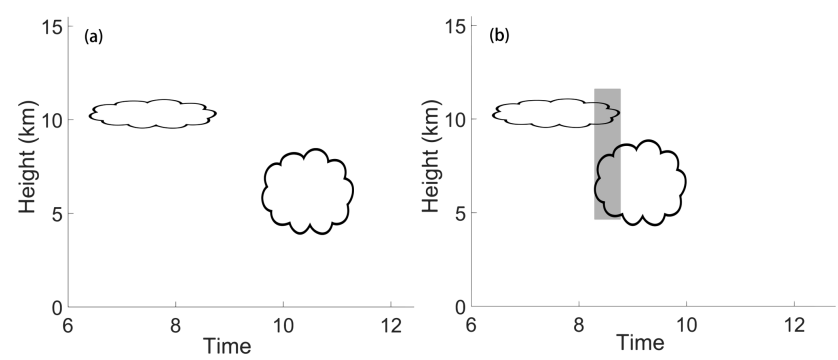

Figure 2. When multilayer clouds exist, the radar CTH is the mean CTH of all cloudy profiles but not upper-level cloud if (a) upperlevel cloud and low-level cloud is situated separately or if (b) upperlevel cloud covers part of the low-level cloud. The CTH of the grey "covered" part of low-level cloud is not considered.

observatory established by the Atmospheric Radiation Measurement, ARM) averaged over a $1 \mathrm{~h}$ interval and the satellite data averaged within a $30 \mathrm{~km} \times 30 \mathrm{~km}$ area for the surfacesatellite comparison. In Holz et al. (2008), the $5 \mathrm{~km}$ averaged CALIOP data were collocated with the $1 \mathrm{~km}$ MODIS data. These collocation methods are designed to satisfy different instrument and observation conditions.

At the IAP site, a collocation scheme is determined according to the local conditions. The moving speed and direction of cloud is always changing, resulting in variable radar scanning length. The MODIS $1 \mathrm{~km}$ spatial resolution is suitable for pixels around the sub-satellite point, but those pixels around the IAP site have flexible spatial resolutions due to the viewing geometry of the individual satellite overpasses (see Fig. 3).

In this study, the ground-based CTH measurements from radar are averaged within $10 \mathrm{~min}$ of the MODIS overpass (MODIS observation time $\pm 5 \mathrm{~min}$ ). All the MODIS CTHs within $5 \mathrm{~km}$ to the IAP site are extracted and averaged to compare with surface radar measurements. A detailed description of the investigation of the optimal collocation scheme, including comparison between collocations using 4 years of MODIS and radar data averaged over different times and areas, will take place in an additional analysis but is briefly discussed here. Figure 4 presents the statistical results from four collocation methods: radar data averaged within 5 min vs. nearest MODIS $\left(D_{\mathrm{m} 0-\mathrm{r} 5}\right)$, radar within $5 \mathrm{~min}$ vs. MODIS averaged over a $5 \mathrm{~km}$ radius $\left(D_{\mathrm{m} 5-\mathrm{r} 5}\right)$, radar within $5 \mathrm{~min}$ vs. MODIS within $30 \mathrm{~km}\left(D_{\mathrm{m} 5-\mathrm{r} 30}\right)$ and

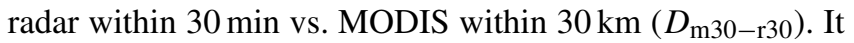
is found that the $D_{\mathrm{m} 5-\mathrm{r} 5}$ is close to the average of four collocation methods.

\subsection{Collocation of the AHI and Ka radar}

Due to the Himawari-8 viewing geometry, an AHI CTH pixel has a fixed $5 \mathrm{~km} \times 5 \mathrm{~km}$ spatial resolution and $10 \mathrm{~min}$ temporal resolution over the IAP site (Fig. 5). Since the AHI presents data every $10 \mathrm{~min}$, the Ka radar data within 

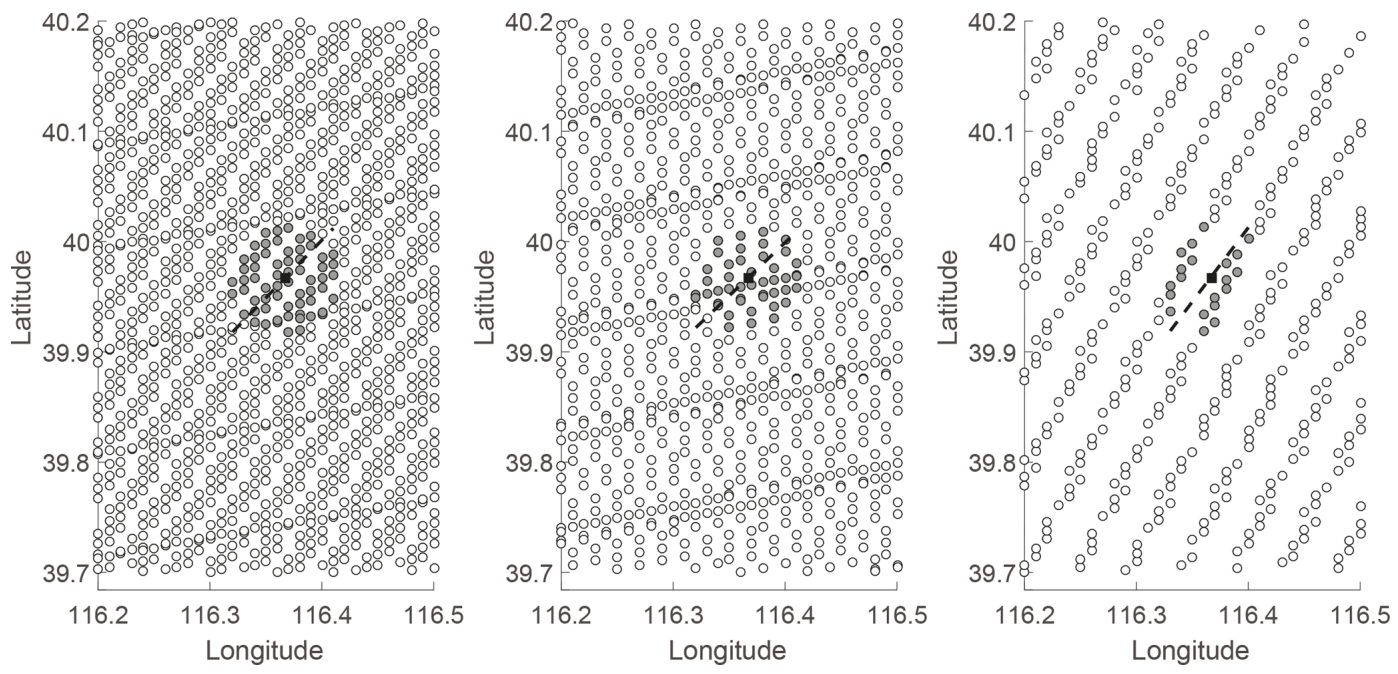

Figure 3. Locations of the Terra MODIS CTHs (circles) and the Ka radar (solid black squares). The three panels exhibit three spatial resolutions of MODIS CTH data due to the changing viewing geometry of the individual satellite overpass. Solid grey circles are MODIS pixels within $5 \mathrm{~km}$ of the IAP site. The possible path scanned by Ka radar is demonstrated by a dashed black line.

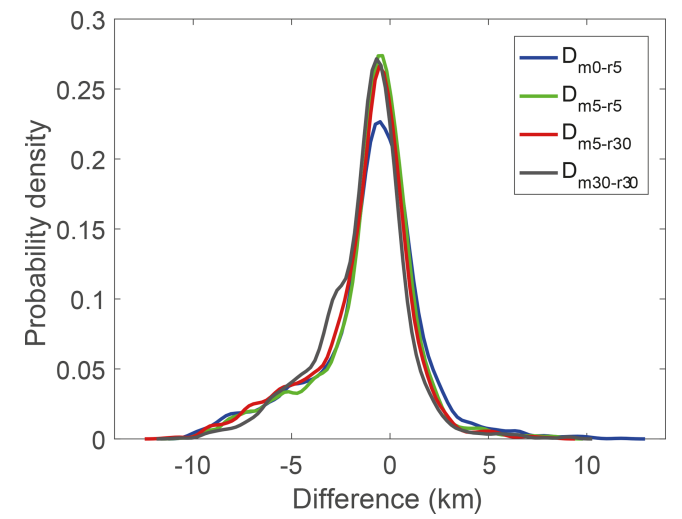

Figure 4. Distributions of the probability density of the CTH difference (MODIS - radar) from four collocation methods. $D_{\mathrm{m} 0-\mathrm{r} 5}$ : radar data averaged within 5 min vs. nearest MODIS; $D_{\mathrm{m} 5-\mathrm{r} 5}$ : radar $5 \mathrm{~min}$ vs. MODIS averaged within $5 \mathrm{~km} ; D_{\mathrm{m} 5-\mathrm{r} 30}$ : radar $5 \mathrm{~min}$ vs. MODIS $30 \mathrm{~km}$; and $D_{\mathrm{m} 30-\mathrm{r} 30}$ : radar $30 \mathrm{~min}$ vs. MODIS $30 \mathrm{~km}$.

10 min of the AHI observation time are extracted and averaged ( $\pm 5 \mathrm{~min}$ ). The AHI CTHs nearest to the IAP site are used for comparison.

\section{Comparison results}

In this study, the CTH difference $\left(D_{\mathrm{mr}}\right)$ between the radar and MODIS data, the CTH difference $\left(D_{\mathrm{ar}}\right)$ between the radar and AHI data, and the CTH difference $\left(D_{\mathrm{am}}\right)$ between the AHI and MODIS data are defined as follows:

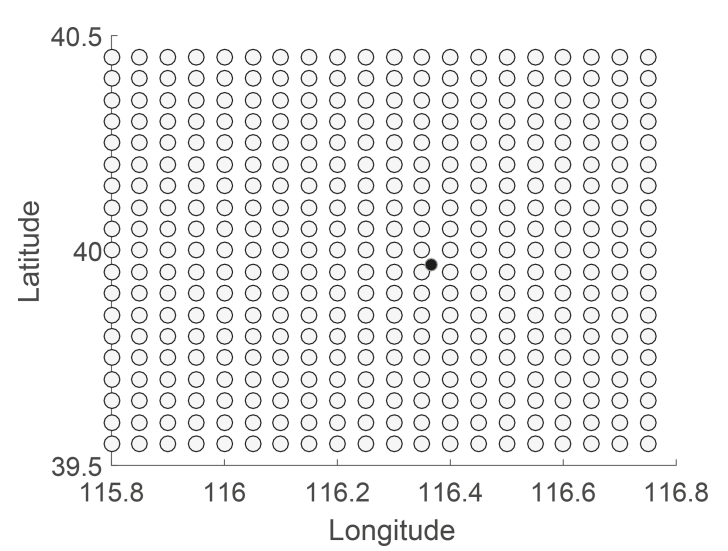

Figure 5. Locations of the AHI CTHs (circles) and the IAP Ka radar (solid black dots). The spatial resolution of the AHI CTH data of the full disk does not change.

$D_{\mathrm{mr}}=H_{\mathrm{m}}-H_{\mathrm{r}}$,
$D_{\mathrm{ar}}=H_{\mathrm{a}}-H_{\mathrm{r}}$,
$D_{\mathrm{am}}=H_{\mathrm{a}}-H_{\mathrm{m}}$,

where $H_{\mathrm{r}}$ is the radar CTH, $H_{\mathrm{m}}$ is the MODIS CTH and $H_{\mathrm{a}}$ is the AHI CTH.

This study uses the radar and satellite data observed from 1 January 2016 to 31 December 2017 for comparison purposes.

\subsection{Comparison between MODIS and Ka radar}

After discarding clear-sky data, Ka radar and MODIS have 963 valid CTH comparison pairs from 1 January 2016 to 31 December 2017 (Fig. 6a). The correlation coefficient 

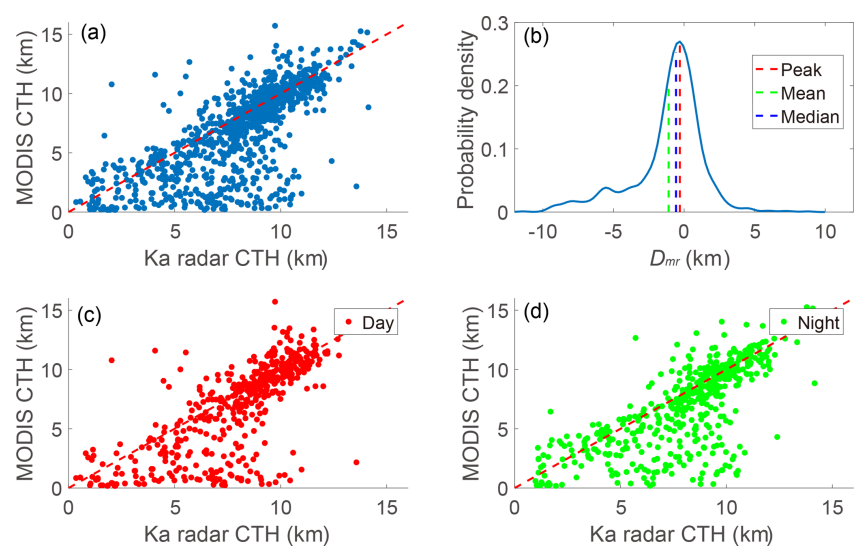

Figure 6. Scatter plot of MODIS CTHs and the Ka radar CTHs from (a) all comparisons, (c) comparisons at daytime and (d) comparisons at night-time. Panel (b) shows the probability density distribution of the $D_{\mathrm{mr}}$, and the peak, mean and median difference is illustrated with dashed red, green and blue lines, respectively.
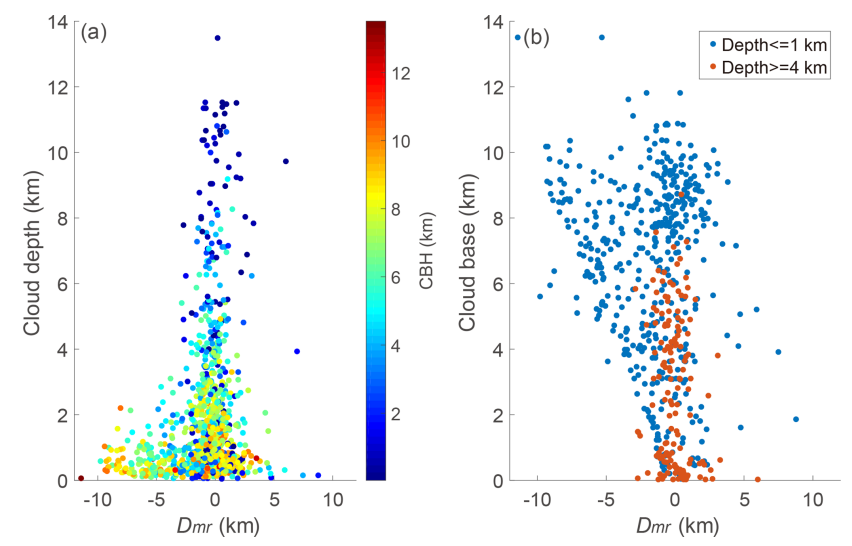

Figure 7. The relationship between (a) the $D_{\mathrm{mr}}$ and cloud depth and (b) the $D_{\mathrm{mr}}$ and the cloud base height $(\mathrm{CBH})$ in cases of cloud depths $<=1 \mathrm{~km}$ (blue) and $>=4 \mathrm{~km}$.

between MODIS CTHs and radar CTHs is 0.72, which show a good agreement with each other. Relative to the $\mathrm{Ka}$ radar, MODIS tends to underestimate the CTHs, by $-1.10 \pm$ $2.53 \mathrm{~km}$ (mean \pm standard deviation, STD, of the $D_{\mathrm{mr}}$ ) on average. Among all comparisons, about $14 \%$ of differences are within $\pm 0.25 \mathrm{~km}, 27 \%$ are within $\pm 0.5 \mathrm{~km}$ and $49 \%$ are within $\pm 1.0 \mathrm{~km}$. The statistical result is very close to the global results reported by Håkansson et al. (2018). Figure 6b presents the probability density distribution of the $D_{\mathrm{mr}}$ but the peak is not centred at zero. Most previous comparison studies used the mean bias to describe the CTH difference (Naud et al., 2002; Holz et al., 2008; Chang et al., 2010; Xi et al., 2014). Håkansson et al. (2018) discussed which statistical method was appropriate for describing a non-Gaussian distribution of CTH difference and found the median was better than the mean to describe the tendency. Here, in Fig. 6b, the peak is at $-0.30 \mathrm{~km}$ (termed "peak" difference) and the me-

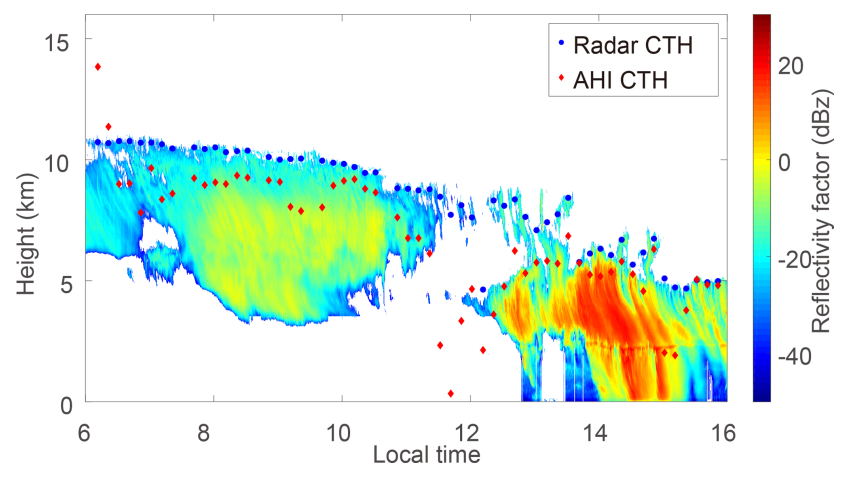

Figure 8. Examples of the Ka radar CTHs (blue dots) and the AHI CTHs (red diamonds) measured on 9 May 2016 from 06:00 to 16:00 (local time: UTC +8 ).

dian is at $-0.57 \mathrm{~km}$ with $2.18 \mathrm{~km}$ IQR (interquartile range). It is clear that the median difference is closer to the peak difference than the mean difference. In this paper, both mean and median differences are used to describe the CTH difference.

From Fig. 6a, it can be seen that most largeunderestimated matches have lower MODIS CTHs, i.e. lower than $4 \mathrm{~km}$. Among all MODIS CTHs, $62 \%$ are greater than $6 \mathrm{~km}$, of which the mean $D_{\mathrm{mr}}$ is $0.0026 \pm 1.43 \mathrm{~km}$; yet, the mean $D_{\mathrm{mr}}$ is $-3.55 \pm 2.99 \mathrm{~km}$ when the MODIS CTHs are less than $4 \mathrm{~km}$. When compared with lower MODIS CTHs, MODIS CTHs greater than $6 \mathrm{~km}$ show better agreement with the Ka radar data. That is, a MODIS CTH greater than $6 \mathrm{~km}$ is more likely to be close to radar CTH than a MODIS CTH less than $4 \mathrm{~km}$. Comparisons between day and night show that the mean $D_{\mathrm{mr}}$ values during the day and night are close to each other (Fig. 6c, d). Terra MODIS and Aqua MODIS show similar accuracy in the CTH retrieval over Beijing.

Uncertainties in the MODIS CTH retrieval depend strongly on cloud depth (Fig. 7a). When cloud becomes thicker, the range of $D_{\mathrm{mr}}$ narrows gradually toward zero. Furthermore, the absolute $D_{\mathrm{mr}}$ decreases with increasing CD (Table 2). Large differences are mainly due to thin clouds $(\mathrm{CD}<1 \mathrm{~km})$. For clouds with $\mathrm{CD}>1 \mathrm{~km}$, the mean $D_{\mathrm{mr}}$ is $-0.48 \pm 1.70 \mathrm{~km}$ and the median (IQR) is $-0.32(1.42) \mathrm{km}$; the mean $D_{\mathrm{mr}}$ is $-0.29 \pm 1.43 \mathrm{~km}$ and median (IQR) is -0.29 $(0.32) \mathrm{km}$ for $\mathrm{CD}>2 \mathrm{~km}$. Figure $7 \mathrm{~b}$ shows that the $D_{\mathrm{mr}}$ changes within small range as the $\mathrm{CBH}$ increases when the $\mathrm{CD}$ is greater than $4 \mathrm{~km}$. It means that there is no obvious relationship between $D_{\mathrm{mr}}$ and $\mathrm{CBH}$ for thick clouds. However, for thin clouds of $\mathrm{CD}<1 \mathrm{~km}$, MODIS tends to greatly underestimate the $\mathrm{CTH}$ of high-level clouds, especially for the clouds with $\mathrm{CBH}>4 \mathrm{~km}$. Clouds with $\mathrm{CBH}>4 \mathrm{~km}$ and $\mathrm{CD}<1 \mathrm{~km}$ account for $37 \%$ of all comparisons, and the mean $D_{\mathrm{mr}}$ is $-2.16 \pm 3.17 \mathrm{~km}$. Clouds of $\mathrm{CBH}<4 \mathrm{~km}$ and $\mathrm{CD}<1 \mathrm{~km}$ account for $10 \%$ of all cases, and the mean $D_{\mathrm{mr}}$ is $-0.37 \pm 2.07 \mathrm{~km}$. Here it is found that the MODIS retrieval algorithm shows large uncertainties for high and thin clouds; i.e. $\mathrm{CBH}$ is $>4 \mathrm{~km}$ and $\mathrm{CD}$ is $<1 \mathrm{~km}$. 

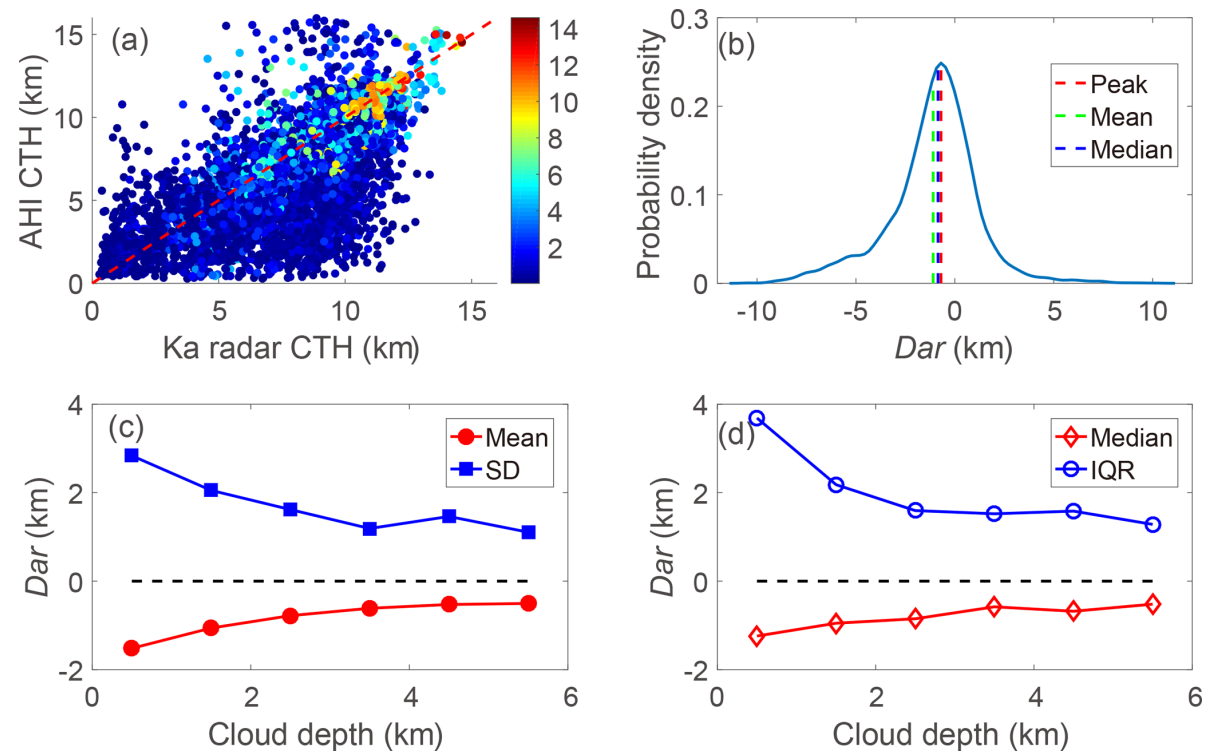

Figure 9. Statistical results of comparisons between Ka radar and AHI. Panel (a) shows the Ka radar CTHs and the AHI CTHs of all comparisons. Panel (b) is the same as Fig. $6 \mathrm{~b}$ but for the $D_{\mathrm{ar}}$. (c) The mean $D_{\mathrm{ar}}$ and the STD changes with CD. (d) The median of $D_{\text {ar }}$ and IQR changes with CD.

Table 2. The median (IQR), mean and standard deviation of $D_{\mathrm{mr}}$ with different CDs (mean $\pm \mathrm{STD}$ ) (unit: km).

\begin{tabular}{lrrrrrr}
\hline CD & $\in(0,1)$ & $\in(1,2)$ & $\in(2,3)$ & $\in(3,4)$ & $\in(4,5)$ & $>5$ \\
\hline Median (IQR) & $-1.14(3.79)$ & $-0.45(1.70)$ & $-0.45(1.38)$ & $-0.28(1.23)$ & $-0.06(1.02)$ & $-0.24(1.43)$ \\
Mean \pm STD & $-1.74 \pm 3.04$ & $-0.91 \pm 2.17$ & $-0.60 \pm 1.61$ & $-0.18 \pm 1.45$ & $-0.24 \pm 1.00$ & $0.01 \pm 1.30$ \\
\hline
\end{tabular}

Among all 963 comparisons, 753 comparisons have only one cloud layer. For single-layer clouds, the mean $D_{\mathrm{mr}}$ is $-1.06 \pm 2.39 \mathrm{~km}$ and the median (IQR) is $-0.55(1.99) \mathrm{km}$, while the mean $D_{\mathrm{mr}}$ is $-1.23 \pm 2.98 \mathrm{~km}$ and the median (IQR) is $-0.70(2.72) \mathrm{km}$ for multilayer clouds. Cloud occurrence frequency (COF) is equal to the number of radar cloudy profiles divided by the total number of radar profiles. It is found that the mean $D_{\mathrm{mr}}$ declines to $-0.39 \pm 1.57 \mathrm{~km}$ for the comparisons when the $\mathrm{CD}$ was $>1 \mathrm{~km}$ and the COF is $>0.5$. Here, the MODIS retrieval algorithm shows higher accuracy for continuous clouds than for broken clouds.

\subsection{Comparison between $\mathrm{AHI}$ and Ka radar}

Figure 8 shows CTHs from the Ka radar and AHI over $10 \mathrm{~h}$ on 9 May 2016. Relative to the comparisons between MODIS and Ka radar, the number of comparisons between the Ka radar and AHI increases due to the increase in temporal resolution of the data. From 1 January 2016 to 31 December 2017, 6719 valid comparisons are found for the CTH comparison.

It can be seen from Fig. 8 that most AHI CTHs are lower than the radar CTHs. All of the $6719 \mathrm{CTH}$ comparisons are shown in Fig. 9a.
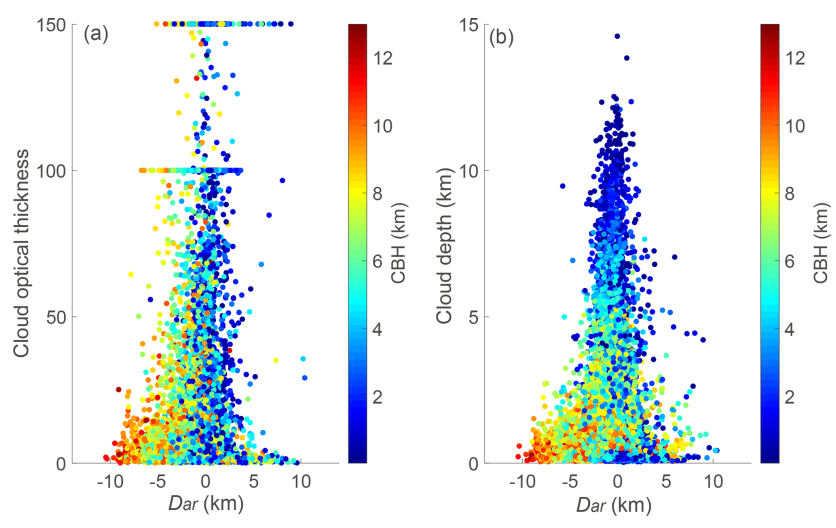

Figure 10. Scatter plot illustrating the relationship of (a) the $D_{\mathrm{ar}}$ and the COTs and (b) the $D_{\text {ar }}$ and the CD.

Statistically, the mean $D_{\text {ar }}$ is $-1.10 \pm 2.27 \mathrm{~km}$, the median $D_{\text {ar }}$ is $-0.85 \mathrm{~km}$ with an IQR of $2.32 \mathrm{~km}$, and the peak is at $-0.70 \mathrm{~km}$ (Fig. 9b). About $11 \%$ of the differences are less than $0.25 \mathrm{~km}, 22 \%$ are within $0.5 \mathrm{~km}$ and $42 \%$ are within $1.0 \mathrm{~km}$. The mean $D_{\mathrm{ar}}$ is close to the mean $D_{\mathrm{mr}}$. The standard deviation is lower due to more comparisons being available. However, the median $D_{\text {ar }}$ and "peak" $D_{\text {ar }}$ is lower than the median $D_{\mathrm{mr}}$ and peak $D_{\mathrm{mr}}$, respectively. 
Table 3. Statistical results of the distribution of $D_{\mathrm{mr}}, D_{\text {ar }}$ and $D_{\text {am }}$ (unit: $\mathrm{km}$ ).

\begin{tabular}{lrrrrr}
\hline & Mean & Median & Peak & STD & IQR \\
\hline$D_{\mathrm{mr}}$ & -1.1 & -0.57 & -0.3 & 2.53 & 2.18 \\
$D_{\mathrm{ar}}$ & -1.1 & -0.85 & -0.7 & 2.27 & 2.32 \\
$D_{\mathrm{am}}$ & -0.64 & -0.43 & -0.18 & 2.36 & 1.93 \\
\hline
\end{tabular}

Cloud depth is also a critical factor impacting the accuracy of the AHI retrieval algorithm (Fig. 9c, d). The mean $D_{\text {ar }}$ decreases as the CD increases, i.e. the mean $D_{\text {ar }}$ is $-1.52 \pm 2.84$ for $\mathrm{CD}<1 \mathrm{~km}$ while the $D_{\text {ar }}$ declines to $-0.76 \pm 1.63 \mathrm{~km}$ for $\mathrm{CD}>1 \mathrm{~km}$. The AHI CTHs illustrate great variation for thin clouds ( $C D<1 \mathrm{~km})$. The mean bias is larger than the median bias when $\mathrm{CD}<2 \mathrm{~km}$. The relationship between the $D_{\mathrm{ar}}$ and the cloud optical thickness (COT) is compared with that between the $D_{\text {ar }}$ and CD (Fig. 10). All COTs are from AHI

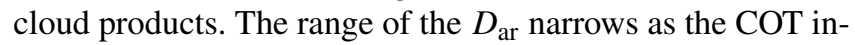
creases, but the distribution is much more scattered than that for $\mathrm{CD}$, which might be due to the COT retrieval errors.

Among all comparisons, $79 \%$ have only one cloud layer. For single-layer clouds, the mean $D_{\text {ar }}$ is $-1.12 \pm 2.25 \mathrm{~km}$ and the median $D_{\text {ar }}$ is $-0.88 \mathrm{~km}$ with an IQR of 2.25 . For multilayer clouds, the mean $D_{\text {ar }}$ is $-0.99 \pm 2.40 \mathrm{~km}$ and the median $D_{\text {ar }}$ is $-0.73 \mathrm{~km}$ with an IQR of 2.69 . The impact of COF on the retrieval accuracy cannot be determined because most of the comparisons with $\mathrm{CD}>1 \mathrm{~km}$ also have COF greater than 0.5 .

\subsection{Comparison between MODIS and AHI}

As just addressed, MODIS and AHI CTH data have different spatial and temporal resolutions. This section compares the MODIS CTHs, averaged using data within 2.5 and $5 \mathrm{~km}$ from the IAP site, with the nearest AHI CTHs, respectively. Observation time interval of comparisons is limited within $5 \mathrm{~min}$. More than 600 valid comparisons are matched and are shown in Fig. 11. The mean $D_{\text {am }}$ is $-0.70 \pm 2.49 \mathrm{~km}$ for the $2.5 \mathrm{~km}$ collocation and $-0.64 \pm 2.36 \mathrm{~km}$ for the $5 \mathrm{~km}$ collocation. The median (IQR) $D_{\text {am }}$ is $-0.45(2.18) \mathrm{km}$ for the $2.5 \mathrm{~km}$ collocation and $-0.43(1.93) \mathrm{km}$ for the $5 \mathrm{~km}$ collocation. The peak $D_{\text {am }}$ is at $-0.17 \mathrm{~km}$ and $-0.18 \mathrm{~km}$, respectively. Statistically, the $5 \mathrm{~km}$ collocation method shows larger CTH bias than the $2.5 \mathrm{~km}$ collocation. These results are close to the results from Kouki et al. (2016), who reported that the mean AHI CTH was smaller than the MODIS CTH by $-0.54 \mathrm{~km}$ based on measurements over $13 \mathrm{~d}$ in August. Also, the CTH difference shows an obvious relationship with COT.

Based on the analysis in Sect. 4.1-4.3, an overview of the statistical results is presented in Table 3. Statistically, MODIS CTHs and AHI CTHs are lower than radar CTHs; the median differences are closer to the peak differences than the mean differences due to the non-Gaussian distribution of difference. Note that the comparisons between MODIS and
$\mathrm{Ka}$ band, between AHI and Ka band, and between MODIS and AHI are based on different comparison samples. Therefore, due to lower median and peak $D_{\mathrm{ar}}$, AHI CTHs are lower on average than MODIS CTHs, though the mean $D_{\mathrm{mr}}$ and mean $D_{\text {ar }}$ are close to each other. It also can be found that the CTH difference between the two satellite instruments is smaller than the difference between the satellite instrument and the ground-based radar.

\subsection{Seasonal variation}

The monthly mean and median $D_{\mathrm{mr}}$ and $D_{\mathrm{ar}}$ are calculated and presented in Fig. 12 as a reference for the meteorological application of the CTH datasets.

Beijing is in northern China and has a typical continental monsoon climate. It is located in the subtropical monsoon zone, with southwest and southeast monsoons prevailing in summer and the northwest monsoon prevailing in winter. Rainfall is greater in summer, with less rain but more snow occurring in winter. The cloud distribution also shows strong seasonal variations. As shown in Fig. 12, the monthly variation in mean $D_{\mathrm{ar}}$ is greater than mean $D_{\mathrm{mr}}$ and shows seasonal characteristics. It is clear that the AHI CTH retrieval algorithm has lower uncertainty in summer (June-August), while it has the largest uncertainty in winter. The MODIS CTH retrieval algorithm also shows better performance in summer than in the other seasons. It is likely due to the seasonal characteristics of cloud distribution that summer has more thick clouds.

\section{Summaries and discussions}

The accuracy of the CTH retrieval algorithm of MODIS and AHI is associated with the instrument, such as the radiance calibration, signal-noise ratio, the spectral response function, and so on. It is also associated with the calculation accuracy of the radiative transfer model and the uncertainty caused by the theoretical assumptions. In an effort to better understand the performance of satellite CTH retrieval algorithms for Beijing, this study evaluates the accuracy of the MODIS and AHI CTH datasets with ground-based radar data based on 2 years of measurements.

Overall, the CTHs retrieved from the two passive sensors on board satellites (Aqua/Terra and HW8) are lower on average than the surface radar data. Furthermore, the retrieval accuracy strongly depends on cloud depth. As the retrieval algorithms determine that the retrieved CTH mostly represents the position of the radiation centre of the clouds, it is reasonable that most $\mathrm{CTH}$ retrieved by MODIS and AHI are lower than the radar CTHs. The CTH difference between two satellite instruments is smaller than the difference between satellite instrument and ground-based radar.

It is found that retrieved MODIS CTHs greater than $6 \mathrm{~km}$ are closer to radar CTH than those lower than $4 \mathrm{~km}$. 

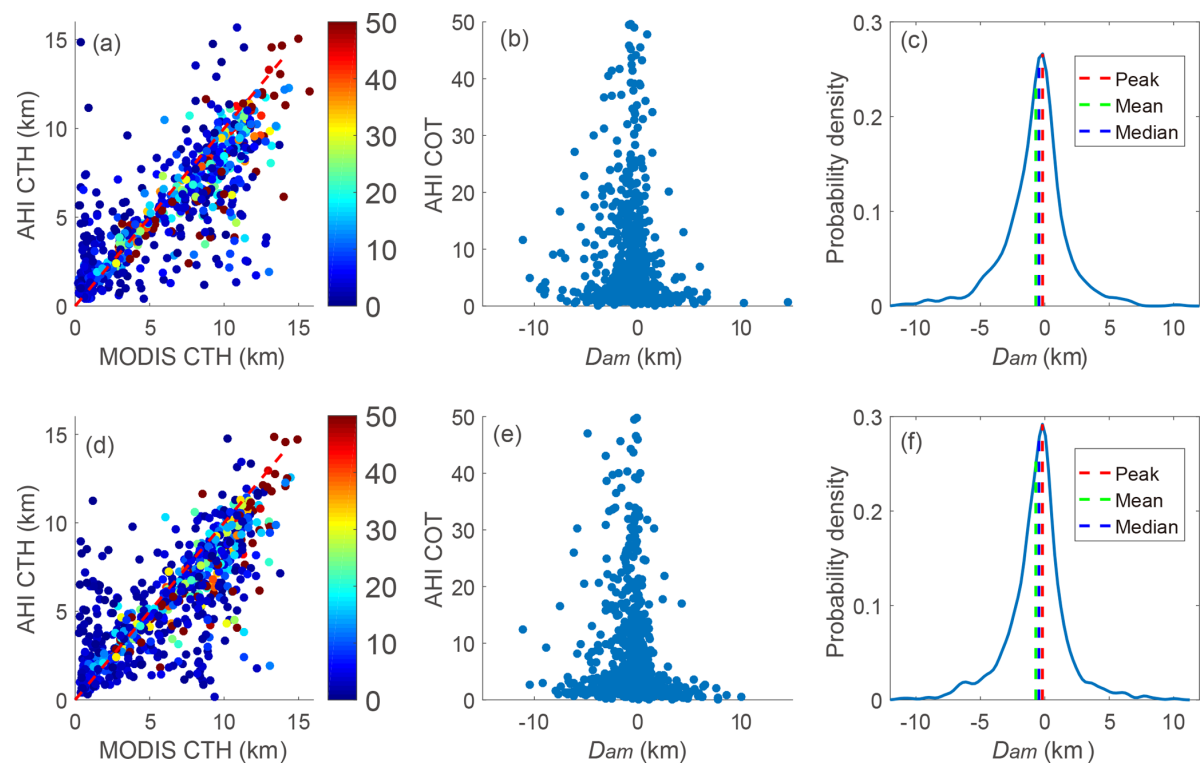

Figure 11. Statistical results of the MODIS CTHs and the nearest AHI CTHs of all comparisons. For the $2.5 \mathrm{~km}$ collocation, panel (a) is the scatter plot of all MODIS CTHs and the AHI CTHs. Panel (b) shows the relationship between the $D_{\text {am }}$ and the COT. Panel (c) presents the probability density distribution of $D_{\mathrm{am}}$, same as Fig. $9 \mathrm{~b}$. Panels $(\mathbf{d}-\mathbf{f})$ are the same as $(\mathbf{a}-\mathbf{c})$ but for a $5 \mathrm{~km}$ radius.
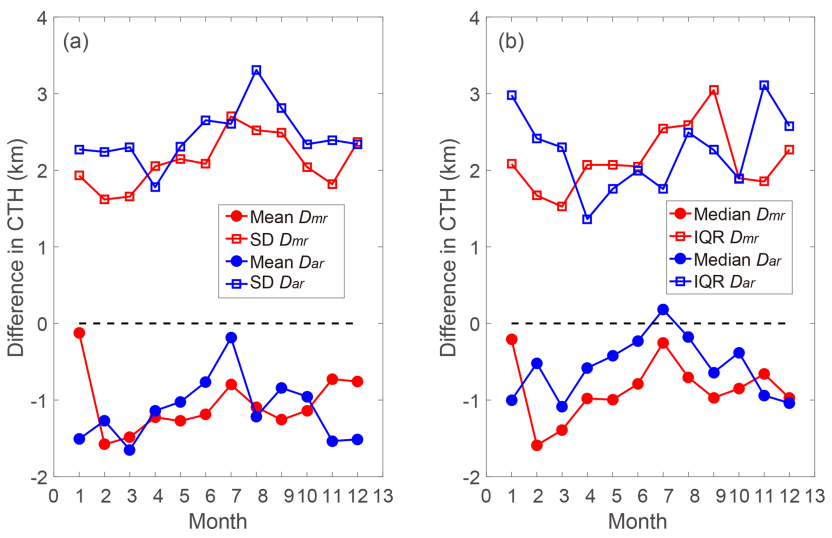

Figure 12. Monthly variations in (a) the mean and standard deviation of the $D_{\mathrm{mr}}$ and the $D_{\mathrm{ar}}$, and (b) the median and IQR of the $D_{\mathrm{mr}}$ and the $D_{\mathrm{ar}}$.

The large differences are mainly from high and thin clouds $(\mathrm{CD}<1 \mathrm{~km})$. In particular, retrieval differences are enlarged when the CBH is greater than $4 \mathrm{~km}$. The mean $D_{\mathrm{mr}}$ for clouds with $\mathrm{CD}>1 \mathrm{~km}$ is $-0.48 \pm 1.70 \mathrm{~km}$ and $-0.29 \pm 1.43 \mathrm{~km}$ for clouds with $\mathrm{CD}>2 \mathrm{~km}$. For the AHI, the mean $D_{\text {ar }}$ decreases as CD increases, i.e. the mean $D_{\text {ar }}$ is $-1.52 \pm 2.84$ for $\mathrm{CD}<1 \mathrm{~km}$, while the $D_{\text {ar }}$ declines to $-0.76 \pm 1.63 \mathrm{~km}$ for $\mathrm{CD}>1 \mathrm{~km}$. The median differences and IQR are also calculated to investigate the $\mathrm{CTH}$ difference, and it is found that those median $\mathrm{CTH}$ biases are smaller than the mean biases due to the non-Gaussian distribution of difference.

Statistical analysis shows that the mean AHI CTHs are lower than the MODIS CTHs over Beijing. On the basis of
2 years of data, the seasonal changes in the $\mathrm{CTH}$ retrieval bias for both sensors is also studied. Both MODIS and AHI retrieval algorithm have the lowest bias in summer.

This study shows the CTH retrieval accuracy of MODIS and $\mathrm{AHI}$ and provides a reference for a better understanding of the climatological trends of clouds based on satellite datasets and to enhance their application in GCM models. However, this study does not consider the causes of the retrieval uncertainties. By combining the results of this study with an analysis of the raw radiance data and source retrieval codes, more insights into improvement of the retrieval algorithms can be obtained in the future.

Data availability. The MODIS product data were obtained from http://ladsweb.nascom.nasa.gov (last access: 16 December 2019). The AHI data were obtained from https://www.eorc.jaxa.jp/ptree/ index.html (last access: 16 December 2019). The radar data used here are available by special request to the corresponding author (huojuan@mail.iap.ac.cn).

Author contributions. JH and DL designed the comparisons, and JH carried them out. SD and YB prepared the ground-based radar data. BL prepared some Himawari data and references. JH prepared the manuscript with contributions from all co-authors.

Competing interests. The authors declare that they have no conflict of interest. 
Acknowledgements. Thanks to the MODIS and the AHI team for sharing their product datasets. We also acknowledge our Ka radar team for their maintenance service during the long-term measurements that made our research possible.

Financial support. This research has been supported by the National Natural Science Foundation of China (grant nos. 41775032 and 41275040).

Review statement. This paper was edited by Piet Stammes and reviewed by Ulrich Hamann and Nina Håkansson.

\section{References}

Ackerman, S. A., Strabala, K. I., Menzel, W. P., Frey, R. A., Moeller, C. C., and Gumley, L. E.: Discriminating clear sky from clouds with MODIS, J. Geophys. Res., 103, 32141-32157, 1998.

Arakawa, A.: The cumulus parameterization problem: Past, present, and future, J. Climate, 17, 2493-2525, 2004.

Atlas, D.: The estimation of cloud parameters by radar, J. Meteor., 11, 309-317, 1954.

Baum, B. A., Menzel, W. P., Frey, R. A., Tobin, D. C., Holz, R. E., Ackerman, S. A., Heidinger, A. K., and Yang, P.: MODIS cloudtop property refinements for Collection 6, J. Appl. Meteor., 51, 1145-1163, 2012.

Bessho, K., Date, K., Hayashi, M., Ikeda, A., Imai, T., Inoue, H., Kumagai, Y., Miyakawa, T., Murata, H., Ohno, T., Okuyama, A., Oyama, R., Sasaki, Y., Shimazu, Y., Shimoji, K., Sumida, Y., Suzuki, M., Taniguchi, H., Tsuchiyama, H., Uesawa, D., Yokota, H., and Yoshida, R.: An introduction to Himawari-8/9 - Japan's new-generation geostationary meteorological satellites, J. Meteorol. Soc. Jpn., 94, 151-183, 2016.

Boucher, O., Randall, D., Artaxo, P., Bretherton, C., Feingold, G., Forster, P., Kerminen, V., Kondo, Y., Liao, H., Lohmann, U., Rasch, P., Satheesh, S., Sherwood, S., Stevens, B., and Zhang, X. Y.: Clouds and Aerosols, in: Climate Change 2013: The Physical Science Basis, Contribution of Working Group I to the Fifth Assessment Report of the Intergovernmental Panel on Climate Change, edited by: Stocker, T. F., Qin, D., Plattner, G., Tignor, M., Allen, S., Boschung, J., Nauels, A., Xia, Y., Bex, V., and Midgley, P.: Cambridge University Press, Cambridge, United Kingdom and New York, NY, USA, 571-657, 2013.

Cess, R. D., Zhang, M. H., Zhou, Y., Jing, X., and Dvortsov, V.: Absorption of solar radiation by clouds: Interpretations of satellite, surface, and aircraft measurements, J. Geophys. Res.-Atmos., 101, 23299-23309, 1996.

Chang, F. L., Minnis, P., Ayers, J. K., McGill, M. J., Palikonda, R., Spangenberg, D. A., Smith Jr., W. L., and Yost, C. R.: Evaluation of satellite - upper troposphere cloud top height retrievals in multilayer cloud conditions during TC4, J. Geophys. Res., 115, https://doi.org/10.1029/2009JD013305, 2010.

Dong, X., Minnis, P., Xi, B., Sun-Mack, S., and Chen, Y.: Comparison of CERES - stratus cloud properties with ground - measurements at the DOE ARM Southern Great Plains site, J. Geophys. Res.-Atmos., 113, https://doi.org/10.1029/2007JD008438, 2008.
Eyre J. R.: A fast radiative transfer model for satellite sounding systems. ECMWF Technical Memoranda, available at: https://www. ecmwf.int/node/9329, 176, https://doi.org/10.21957/xsg8d92y3, 1991.

Görsdorf, U., Lehmann, V., Bauer-Pfundstein, M., Peters, G., Vavriv, D., Vinogradov, V., and Volkov, V.: A $35 \mathrm{GHz}$ polarimetric Doppler radar for long-term observations of cloud parameters - Description of system and data processing, J. Atmos. Ocean. Tech., 32, 675-690, 2015.

Håkansson, N., Adok, C., Thoss, A., Scheirer, R., and Hörnquist, S.: Neural network cloud top pressure and height for MODIS, Atmos. Meas. Tech., 11, 3177-3196, https://doi.org/10.5194/amt11-3177-2018, 2018.

Ham, S. H., Sohn, B. J., Yang, P., and Baum, B. A.: Assessment of the quality of MODIS cloud products from radiance simulations, J. Appl. Meteor., 48, 1591-1612, 2009.

Hamada, A. and Nishi, N.: Development of a cloud-top height estimation method by geostationary satellite split-window measurements trained with CloudSat data, J. Appl. Meteor., 49, 20352049, 2010.

Hamann, U., Walther, A., Baum, B., Bennartz, R., Bugliaro, L., Derrien, M., Francis, P. N., Heidinger, A., Joro, S., Kniffka, A., Le Gléau, H., Lockhoff, M., Lutz, H.-J., Meirink, J. F., Minnis, P., Palikonda, R., Roebeling, R., Thoss, A., Platnick, S., Watts, P., and Wind, G.: Remote sensing of cloud top pressure/height from SEVIRI: analysis of ten current retrieval algorithms, Atmos. Meas. Tech., 7, 2839-2867, https://doi.org/10.5194/amt-72839-2014, 2014.

Huo, J. and $\mathrm{Lu}, \mathrm{D}$.: Cloud determination of all-sky images under low-visibility conditions, J. Atmos. Ocean. Tech., 26, 2172 2181, 2009.

Huo, J., Bi, Y., Lü, D., and Duan, S.: Cloud Classification and Distribution of Cloud Types in Beijing Using Ka-Band Radar Data, Adv. Atmos. Sci., 36, 793-803, 2019.

King, M., Tsay, S., Platnick, S., Wang, M., and Liou, K.: Cloud Retrieval: Algorithms for MODIS: Optical thickness, effective particle radius, and thermodynamic phase, Algorithm Theoretical Basis Document, ATBD-MOD-05, 83 pp., 1998.

Kouki, M., Hiroshi, S., Ryo, Y., and Toshiharu, I.: Algorithm theoretical basis document for cloud top height product, Meteorolgical Satellite Center Technical Note, https://www.data.jma.go. jp/mscweb/technotes/msctechrep61-63.pdf (last access: 19 June 2019), 2016.

Liou, K. N.: Radiation and cloud rrocesses in the atmosphere: theory, observation, and modeling, Oxford University Press, 487 pp, 1992.

Marchand, R.: Trends in ISCCP, MISR, and MODIS cloud-topheight and optical-depth histograms, J. Geophys. Res.-Atmos. 118, 1941-1949, 2013.

Marchand, R., Ackerman, T., Smyth, M., and Rossow, W.: A review of cloud top height and optical depth histograms from MISR, ISCCP, and MODIS, J. Geophys. Res.-Atmos., 115, https://doi.org/10.1029/2009JD013422, 2010.

Menzel, W., Frey, R., Zhang, H., Wylie, D., Moeller, C., Holz, R., Maddux, B., Baum, B., Strabala, K., and Gumley, L.: MODIS global cloud-top pressure and amount estimation: algorithm description and results, J. Appl. Meteorol., 47, 1175-1198, 2008. 
Mouri, K., Izumi, T., Suzue, H., and Yoshida, R.: Algorithm Theoritical Basis Document of cloud type/phase product, Meteorological Satellite Center, Technical Note, 61, 19-31, 2016.

Naud, C., Muller, J. P., and Clothiaux, E. E.: Comparison of cloud top heights derived from MISR stereo and MODIS $\mathrm{CO}_{2}$, Geophys. Res. Lett., 29, 421-424, 2002.

Nieman, S. J., Schmetz, J., and Menzel, W. P.: A comparison of several techniques to assign heights to cloud tracers, J. Appl. Meteorol., 32, 1559-1568, 1993.

Pavolonis, M. J. and Heidinger, A. K.: Daytime cloud overlap detection from AVHRR and VIIRS, J. Appl. Meteorol., 43, 762-778, 2004.

Pincus, R., Platnick, S., Ackerman, S. A., Hemler, R. S., and Patrick Hofmann, R. J.: Reconciling simulated and observed views of clouds: MODIS, ISCCP, and the limits of instrument simulators, J. Climate, 25, 4699-4720, 2012.

Remer, L. A., Kleidman, R. G., Levy, R. C., Kaufman, Y. J., Tanré, D., Mattoo, S., Martins, J. V., Ichoku, C., Koren, I., Yu, H., and Holben, B. N.: Global aerosol climatology from the MODIS satellite sensors, J. Geophys. Res.-Atmos., 113, https://doi.org/10.1029/2007JD009661, 2008.

Ramanathan, V. L. R. D., Cess, R. D., Harrison, E. F., Minnis, P., Barkstrom, B. R., Ahmad, E., and Hartmann, D.: Cloud-radiative forcing and climate: Results from the Earth Radiation Budget Experiment, Science, 243, 57-63, 1989.

Rodell, M. and Houser, P. R.: Updating a land surface model with MODIS-derived snow cover, J. Hydrometeorol., 5, 1064-1075, 2004.

Roskovensky, J. K. and Liou, K. N.: Simultaneous determination of aerosol and thin cirrus optical depths over oceans from MODIS data: Some case studies, J. Atmos. Sci., 63, 2307-2323, 2006.

Rossow, W. B. and Schiffer, R. A.: Advances in understanding clouds from ISCCP, Bound.-Lay. Meteorol., 80, 2261-2288, 1999.

Schmetz, J., Holmlund, K., Hoffman, J., and Strauss, B.: Operational cloud motion winds from Meteosat infrared images, J. Appl. Meteorol., 32, 1207-1225, 1993.

Schiffer, R. A. and Rossow, W. B.: The International Satellite Cloud Climatology Project (ISCCP): The first project of the world climate research programme, Bound.-Lay. Meteorol., 64, 779-784, 1983.
Smith, W. L. and Platt, C. M. R.: Comparison of satellite-deduced cloud heights with indications from radiosonde and groundbased laser measurements, J. Appl. Meteorol., 17, 1796-1802, 1978.

Stephens, G. L. and Kummerow, C. D.: The remote sensing of clouds and precipitation from space: A review, J. Atmos. Sci., 64, 3742-3765, 2007.

Stubenrauch, C. J., Del Genio, A. D., and Rossow, W. B.: Implementation of subgrid cloud vertical structure inside a GCM and its effect on the radiation budget, J. Climate, 10, 273-287, 1997.

Wang, T., Luo, J., Liang, J., Wang, B., Tian, W., and Chen, X.: Comparisons of AGRI/FY-4A cloud fraction and cloud top rressure with MODIS/Terra measurements over East Asia, J. Meteorol. Res., 33, 705-719, 2019.

Weisz, E., Li, J., Menzel, W. P., Heidinger, A. K., Kahn, B. H., and Liu, C. Y.: Comparison of AIRS, MODIS, CloudSat and CALIPSO cloud top height retrievals, Geophys. Res. Lett., 34, https://doi.org/10.1029/2007GL030676, 2007.

Wetherald, R. T. and Manabe, S.: Cloud feedback processes in a general circulation model, J. Atmos. Sci., 45, 1397-1416, 1988.

Xi, B., Dong, X., Minnis, P., and Sun-Mack, S.: Comparison of marine boundary layer cloud properties from CERES - Edition 4 and DOE ARM AMF measurements at the Azores, J. Geophys. Res.-Atmos., 119, 9509-9529, https://doi.org/10.1002/2014JD021813, 2014.

Xiao, P., Huo, J., and Bi, Y.: Ground-based Ka- band cloud radar data quality control. Journal of Chengdu University of Information Technology, Journal of Chengdu University of Information Technology, 33, 129-136, https://doi.org/110.16836/j.cnki.jcuit.12018.16802.16005, 2018.

Zhou, Q., Zhang, Y., Li, B., Li, L., Feng, J., Jia, S., Lv, S., Tao, F., and Guo, J.: Cloud-base and cloudtop heights determined from a ground-based cloud radar in Beijing, China, Atmos. Environ., 201, 381-390, https://doi.org/310.1016/j.atmosenv.2019.1001.1012, 2019. 